\title{
Família que convive com pessoa com transtorno mental: genograma e ecomapa
}

Family living with people with mental disorders: genogram and ecomap

Familia viviendo com una persona con trastornos mentales: genograma y ecomap

\section{Ariane Naidon Cattani ${ }^{I}$, Ana Paula Vargas Ronsani ${ }^{I I}$, Lisiane dos Santos Welter ${ }^{\mathrm{II}}$, Amanda de Lemos Mello ${ }^{\mathrm{IV}}$, Daiana Foggiato de Siqueirav ${ }^{\mathrm{v}}$, Marlene Gomes Terra ${ }^{\mathrm{VI}}$}

Resumo: Objetivo: analisar a estrutura, os vínculos e a rede de apoio de uma família que convive com uma pessoa com transtorno mental por meio da construção do genograma e ecomapa. Método: estudo qualitativo, exploratório e descritivo, realizado com duas pessoas de uma família que convive com pessoa com transtorno mental, em um hospital, localizado no Rio Grande do Sul. Utilizou-se entrevista semiestruturada norteada pelo Guia para Avaliação e Intervenção na Família. A análise consistiu na construção do genograma e ecomapa, com auxílio de um software de genealogia. Resultados: os vínculos familiares são fracos. A rede de apoio é centrada no serviço de emergência, ambulatorial e internação, há precariedade de serviços substitutivos e de locais para reinserção social. Conclusão: a implementação do genograma e ecomapa na assistência a pessoas com transtornos mentais são ferramentas que auxiliam no planejamento do cuidado e intervenções no contexto familiar.

Descritores: Saúde Mental; Transtornos Mentais; Família; Enfermagem; Enfermagem Psiquiátrica

\footnotetext{
I Enfermeira. Especialista em Saúde Mental no Sistema Público de Saúde/UfSM. Mestranda do Programa de Pós-Graduação em Enfermagem/UFSM. Universidade Federal de Santa Maria. Santa Maria, RS, Brasil. E-mail: arianecattani@yahoo.com.br - ORCID: https://orcid.org/0000-0002-3365-9237

${ }^{\text {II }}$ Assistente Social. Especialista em Saúde Mental no Sistema Público de Saúde/UFSM. Mestranda do Programa de Pós-Graduação em Serviço Social/PUCRS. Pontifícia Universidade Católica do Rio Grande do Sul. Porto Alegre, RS, Brasil. E-mail: paularonsani@hotmail.com - ORCID: https://orcid.org/0000-0001-9083-2721

III Psicóloga. Especialista em Saúde Mental no Sistema Público de Saúde/UfSM. Mestranda do Programa de Pós-Graduação em Psicologia/UFSM. Universidade Federal de Santa Maria. Santa Maria, RS, Brasil. E-mail: lisianewelter27@gmail.com - ORCID: https://orcid.org/0000-0002-6781-0847

IV Enfermeira. Mestre em Enfermagem. Doutoranda do Programa de Pós-Graduação em Enfermagem/UFSM. Professora Substituta do Departamento de Enfermagem e do Departamento de Serviço Social/UFSM. Universidade Federal de Santa Maria. Santa Maria, RS, Brasil. Email: amandamello6@yahoo.com - ORCID: https://orcid.org/0000-0002-0485-1801

v Enfermeira. Doutora em Enfermagem. Professora Adjunta do Departamento de Enfermagem/UFSM. Universidade Federal de Santa Maria. Santa Maria, RS, Brasil. E-mail: daianasiqueira@yahoo.com.br - ORCID: https://orcid.org/0000-0002-8592-379X

${ }^{V I}$ Enfermeira. Pós-doutora em Enfermagem. Professora Associada - Nível 2 do Departamento de Enfermagem e do Programa de Pós-Graduação em Enfermagem/UFSM. Universidade Federal de Santa Maria. Santa Maria-RS, Brasil. E-mail: martesm@hotmail.com.br - ORCID: https://orcid.org/0000-0001-9402-561X
} 
Família que convive com pessoa com transtorno mental: genograma e ecomapa| 2

\begin{abstract}
Aim: to analyze the structure, bonds and support network of a family that lives with a person with mental disorder through the construction of the genogram and ecomap. Method: a qualitative, exploratory and descriptive study, conducted with two people from a family living with a person with mental disorder, in a hospital located in Rio Grande do Sul. A semi-structured interview guided by the Guide for Evaluation and Family Intervention was used. The analysis consisted of the construction of the genogram and ecomap, with the aid of genealogy software. Results: family bonds are weak. The support network is centered on emergency, outpatient and inpatient services; there is a precariousness of substitute services and places for social reintegration. Conclusion: the implementation of the genogram and ecomap in care for people with mental disorders are tools that help in the planning of care and interventions in the family context.
\end{abstract}

Descriptors: Mental Health; Mental Disorders; Family; Nursing; Psychiatric Nursing

Resumen: Objetivo: analizar la estructura, los vínculos y la red de apoyo de una familia que vive con una persona con trastorno mental a través de la construcción del genograma y el ecomap. Método: estudio cualitativo, exploratorio y descriptivo, realizado con dos personas de una familia que vive con una persona con trastorno mental, en un hospital ubicado en Rio Grande do Sul. Se utilizó una entrevista semiestructurada guiada por la Guía de Evaluación e Intervención Familiar. El análisis consistió en la construcción del genograma y ecomap, con la ayuda del software de genealogía. Resultados: los lazos familiares son débiles. La red de apoyo se centra en servicios de emergencia, ambulatorios y de hospitalización, existe la precariedad de los servicios sustitutos y lugares para la reintegración social. Conclusión: la implementación del genograma y el ecomap en la atención de personas con trastornos mentales son herramientas que ayudan en la planificación de la atención e intervenciones en el contexto familiar.

Descriptores: Salud Mental; Trastornos Mentales; Familia; Enfermería; Enfermería Psiquiátrica

\title{
Introdução
}

A família pode ser considerada como um sistema aberto interconectado com outras estruturas sociais, composto por pessoas que compartilham uma relação de cuidado (proteção, alimentação, socialização). Os familiares estabelecem vínculos afetivos, de convivência, de parentesco consanguíneo ou não, condicionados por valores socioeconômicos e culturais determinados em um dado contexto geográfico, histórico e cultural. ${ }^{1}$

Neste ínterim, as famílias desenvolvem, junto aos profissionais de saúde, um papel colaborativo na assistência à pessoa com transtorno mental, ofertando cuidado e compartilhando momentos difíceis. Esse cuidado caracteriza-se pelo auxílio em atividades cotidianas: no autocuidado, no trabalho, no lazer e na inserção social no contexto domiciliar e comunitário. $^{2}$ Ainda, a família pode vir a ser corresponsável em acompanhar a pessoa aos 
serviços de saúde, auxiliar nas medicações, arcar com gastos no tratamento e superar as dificuldades dessas tarefas. ${ }^{3}$

Historicamente, a família nem sempre foi vista de maneira positiva no cuidado de um familiar que adoece mentalmente. Nas sociedades pré-capitalistas, o cuidado era remetido à família e, na sua ausência, a pessoa com transtorno mental tornava-se uma questão pública, de justiça ou de deliberação do rei. No Século XX, com os avanços de saberes como a psicanálise e o movimento de higiene mental, passou-se a culpabilizar a família pelo surgimento de uma pessoa com transtorno mental, que se afastava do seu ambiente familiar, fortalecendo as instituições psiquiátricas e a cultura do isolamento social. ${ }^{4}$

Em 1950, os estudos sobre o tema família ganharam visibilidade com o surgimento das terapias familiares, com enfoque nas mudanças dos padrões relacionais e de comunicação no sistema familiar. Porém, foi a partir da Lei № 10.216 de 06 de abril de 2001, Lei da Reforma Psiquiátrica, que a relação da família com a pessoa com transtorno mental passou a ter maior atenção, pois com a desinstitucionalização, a família começou a ser considerada como parte do cuidado. ${ }^{4}$

Entretanto, por vezes, a família é desprovida de preparo e se vê frente à dificuldades ao assumir o papel de cuidadora, como a não adesão ao tratamento pelo seu familiar, a sobrecarga, gastos financeiros, entre outras. ${ }^{2}$ Em alguns casos, essas situações podem contribuir para que desordens emocionais ocorram no contexto familiar. Além disso, deve-se considerar que possíveis quadros de isolamento, automutilação e agressividade na pessoa com transtorno mental podem gerar ansiedade, raiva, medo e culpa em quem a cuida. ${ }^{5}$

Com base nesses aspectos, os familiares estão sujeitos à sobrecarga física e mental, pois pode haver comprometimento da vida social, ocupacional e financeira. ${ }^{2}$ Para minimizar essas dificuldades, as relações externas também contribuem para o cuidado. Estas relações caracterizam a rede de apoio, constituída por pessoas e/ou instituições que participam desse 
Família que convive com pessoa com transtorno mental: genograma e ecomapa| 4

processo. ${ }^{6}$ Essa rede pode amparar a família em diferentes aspectos como psicológico, social, financeiro, entre outros, auxiliando no processo de adaptação para o cuidado e para a vida. ${ }^{7}$

A partir da elaboração do genograma e do ecomapa é possível utilizar os dados obtidos para realização de intervenções que busquem melhorar o vínculo afetivo e o cuidado aos usuários e seus familiares, auxiliá-la a perceber a dinâmica, reestruturar comportamentos e melhorar relações. Também, permite aos profissionais de saúde repensar práticas com o intuito de aperfeiçoá-las, bem como identificar fragilidades e potencialidades, possibilitando a avaliação e planejamento de estratégias conjuntas, que contribuam para o enfrentamento de problemas vivenciados pela família. Os efeitos disso são estratégias terapêuticas mais adequadas, melhorando a qualidade de vida dos usuários e de seus familiares. ${ }^{8}$

Nesta perspectiva, o presente estudo teve como questão de pesquisa: como se configura a estrutura, os vínculos e a rede de apoio de uma família que convive com uma pessoa com transtorno mental? E por objetivo analisar a estrutura, os vínculos e a rede de apoio de uma família que convive com uma pessoa com transtorno mental por meio da construção do genograma e ecomapa.

\section{Método}

Trata-se de um estudo qualitativo, exploratório e descritivo. Foi realizado com duas pessoas integrantes de uma família, nomeadas de modo fictício, Ana (mãe) e Abel (pai). Junto à pessoa índice, Alex, constituem a "Família A".

Estipulou-se como critérios de seleção da família para entrevista: deveria ter um de seus integrantes com diagnóstico médico de algum transtorno mental, internado no período da coleta de dados e possuir maior número de reinternações registradas na Unidade de Atenção Psicossocial (UAP) de um Hospital Geral de Ensino, público, localizado em um município no Estado do Rio Grande do Sul. Como critério de inclusão dos familiares: integrantes mais próximos da pessoa com 
transtorno mental, por melhor compreender o seu cotidiano. E, como critério de exclusão: não apresentar condições de se comunicar verbalmente, sendo esta avaliação realizada pela pesquisadora com base na percepção da equipe multiprofissional do serviço.

A UAP é uma unidade de internação de um hospital de grande porte, composta pela equipe de enfermagem, psicólogo, assistente social, terapeuta ocupacional e psiquiatras. Além disso, conta com a inserção da Residência Multiprofissional em Saúde e Médica. Possui enfermarias masculinas e femininas, totalizando 30 leitos, onde as pessoas são alocadas conforme critérios da equipe, atendendo pessoas com transtorno mental.

Os integrantes foram convidados para participar da pesquisa de maneira intencional, pois se optou pelos integrantes mais próximos, o que foi constatado a partir de confirmação verbal da equipe do serviço e nas evoluções do prontuário da pessoa índice. Alex não participou da entrevista devido déficit cognitivo importante, o que gera dificuldade de compreensão da entrevista e de concentração para respondê-la.

Utilizou-se o Guia para Avaliação e Intervenção na Família para nortear as entrevistas. Esse preconiza que genograma tem a finalidade de fornecer uma visão geral da família, sua estrutura, bem como dados sociodemográficos, entre outros. Ao realizá-lo, é importante apresentar pelo menos três gerações, pois isto propicia informações sobre relacionamentos ao longo do tempo. O ecomapa busca apresentar informações a respeito dos relacionamentos da família com elementos externos, retratando os vínculos importantes entre a família e o mundo, e demonstrando ainda o fluxo ou a falta de recursos e as privações da família. Ambos possibilitam uma avaliação estrutural da família, o genograma de maneira interna e o ecomapa externa. ${ }^{9}$

Para tanto, com cada um dos integrantes da família foi realizada uma entrevista semiestruturada, com duração média de 50 minutos. O roteiro da entrevista foi organizado em dois momentos, a partir de um instrumento elaborado pelas pesquisadoras. O primeiro destinado à caracterização dos entrevistados e ao registro de dados relativos à pessoa com transtorno mental. O 
Família que convive com pessoa com transtorno mental: genograma e ecomapa| 6

segundo voltado a abordar a temática central do estudo, contendo a seguinte questão norteadora: fale-me sobre o seu contexto familiar, desde o diagnóstico do seu familiar/início do acompanhamento até o presente momento. As entrevistas foram registradas em um gravador digital com o consentimento prévio dos participantes e, posteriormente, transcritas na integra. Os encontros ocorreram em uma sala reservada no hospital no mês de agosto de 2017.

A análise dos dados consistiu-se na leitura aprofundada das entrevistas e construção dos diagramas do genograma e ecomapa, desenhados, inicialmente, junto à família durante as entrevistas e detalhados pela pesquisadora de acordo com os dados obtidos. Para auxiliar essa construção, utilizou-se um software de genealogia disponível na internet, denominado GenoPro $^{\circledR}$ versão 2016. Os desenhos do genograma e ecomapa foram validados pela família. Comunicou-se os objetivos e aspectos éticos da pesquisa aos participantes, que assinaram o Termo de Consentimento Livre e Esclarecido (TCLE). Preservou-se o anonimato dos entrevistados por meio da adoção de nomes fictícios determinados pela pesquisadora.

Este estudo foi aprovado pelo Comitê de Ética em Pesquisa e seguiu os preceitos éticos da Resolução 466/12, do Conselho Nacional da Saúde. ${ }^{10}$ Sob o parecer nํ 2.009.636, processo CAAE 65186917.8.0000.5346, emitido no dia 10 de abril de 2017.

\section{Resultados}

A família se mostrou interessada, disposta e colaborativa durante o processo. O seu genograma por ser visualizado na Figura 1. 


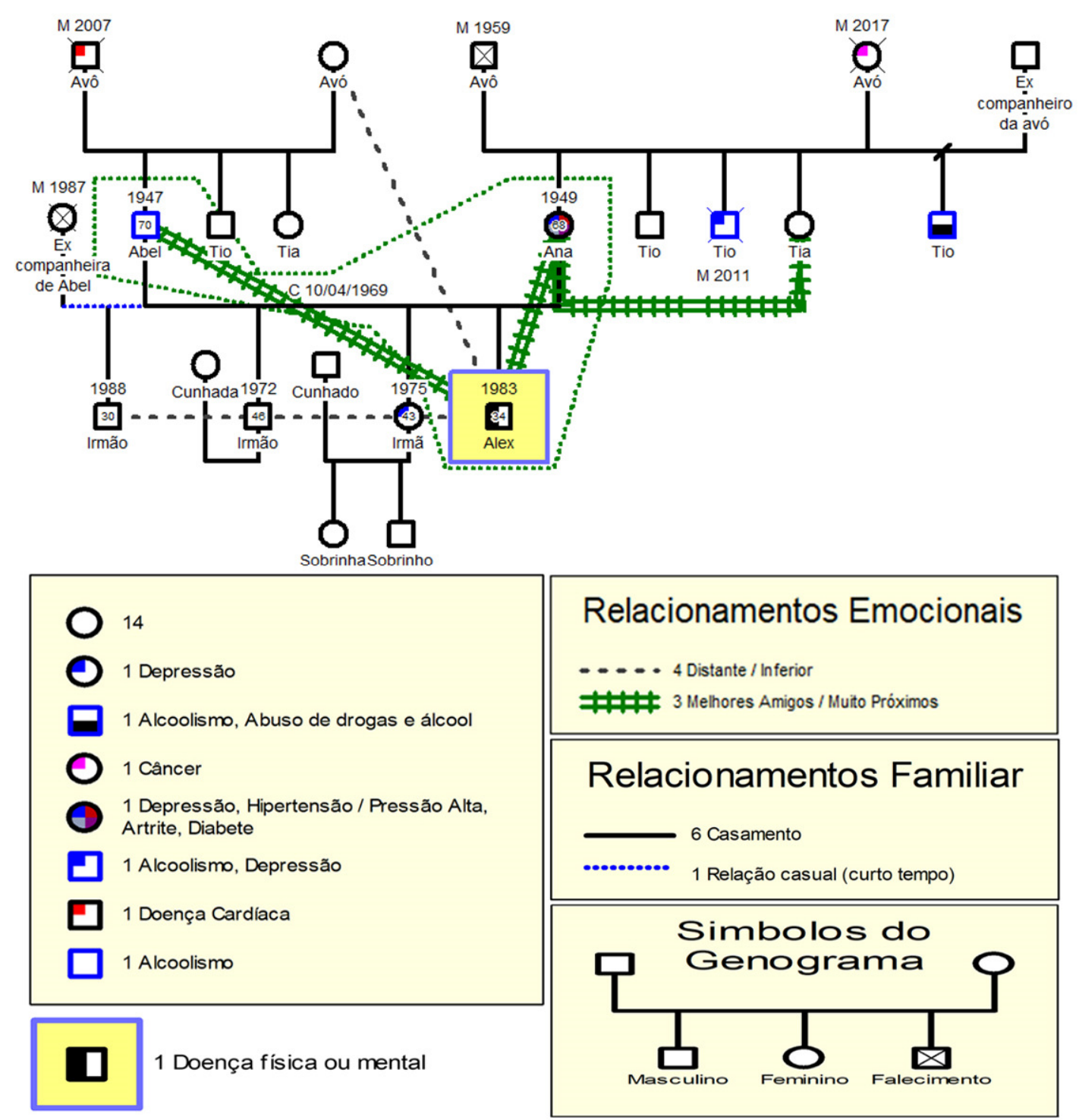

Figura 1 - Genograma da Família A. Rio Grande do Sul, Brasil, 2017

As entrevistas foram realizadas com os pais de Alex, 34 anos. Alex estudou até a $4^{\mathrm{a}}$ série e recebe Beneficio de Prestação Continuada (BPC). Foi diagnosticado com deficiência intelectual moderada e apresentou os primeiros episódios de agressividade em 1997 aos 14 anos, quando iniciou acompanhamento psiquiátrico no Ambulatório de Psiquiatria do Hospital. Sua primeira internação na UAP foi dia 07/11/2002 aos 19 anos. Até o momento da coleta de dados, com base nos prontuários, informação dos pais e da equipe da UAP, Alex possuía mais de 30 internações. 
Família que convive com pessoa com transtorno mental: genograma e ecomapa| 8

Ana (mãe), 68 anos, é do lar e aposentada. Abel (pai), 70 anos, também é aposentado e cuida de uma chácara da família. Ana e Abel são casados há 48 anos e têm três filhos, sendo uma mulher e dois homens. Abel possui um filho de uma relação extraconjugal, Ana assumiu a maternidade, pois a mãe da criança cometeu suicídio com arma de fogo quando esta tinha cinco meses de idade.

O avô materno de Alex era agricultor e faleceu em 1959, a avó era do lar e faleceu em decorrência de câncer renal em abril de 2017. O avô paterno, que era ferroviário, faleceu devido a complicações cardíacas em 2007 e a avó, aposentada, está viva, porém não mantém contato com Alex.

Alex tem um tio e uma tia por parte de pai. Por parte de mãe, tem uma tia e três tios, dois dos tios alcoolistas, um destes cometeu suicídio por enforcamento em 2011, o qual realizava tratamento para depressão.

Alex possui três irmãos, 30, 43 e 46 anos, que residem no mesmo município, porém, segundo relatos de Ana e Abel, auxiliam pouco no cuidado e não mantém vínculos com Alex. Ana e Abel demonstram-se sobrecarregados, pois são os principais responsáveis pelo cuidado. Abel está sempre envolvido com as questões burocráticas das internações e instituições de longa permanência.

Tudo quem faz é o Abel, corre atrás de tudo é o Abel [...]. Eu sempre presente, num sábado venho na visita e no outro vou para fora [chácara] porque cansa, para arejar um pouco a cabeça. (Ana)

Os familiares tornaram-se os principais provedores de cuidados e apoio. No caso desta família, Ana possui artrose, pré-diabetes, hipertensão e faz uso de medicações antidepressivas. Abel já esteve internado em uma unidade de tratamento para usuários de álcool e outras drogas, mas não realizou acompanhamento após a alta.

Pode-se perceber que é uma família vulnerável psicossocialmente, em que o cuidado à saúde de Alex é centrado nos seus pais, que são idosos. Nesse sentido, torna-se importante a 
utilização do ecomapa para conhecer os vínculos entre a família e visualizar sua rede de apoio, conforme Figura 2.

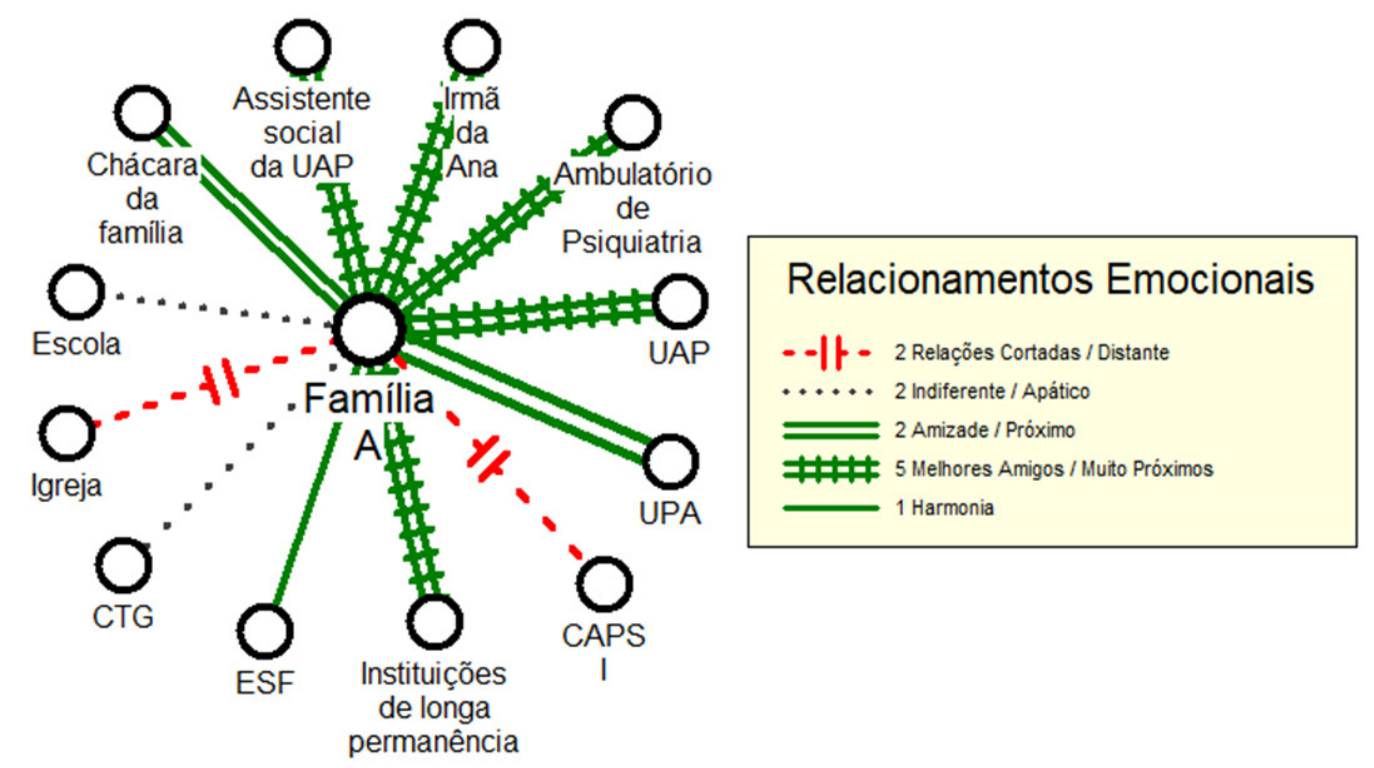

Figura 2 - Ecomapa da Família A. Rio Grande do Sul, Brasil, 2017

Nota: UAP (Unidade de Atenção Psicossocial); UPA (Unidade de Pronto Atendimento); CAPS (Centro de Atenção Psicossocial); ESF (Estratégia de Saúde da Família); CTG (Centro de Tradições Gaúchas).

Quando se realizou a entrevista, Ana e Abel não relataram sérios conflitos, porém a família não apresentava muitos vínculos fortes entre seus integrantes. Ana possui um bom vínculo com sua irmã, referindo que esta a escuta nos momentos difíceis.

A família possui vínculo forte com a assistente social residente da UAP, que acompanha o caso junto com outros profissionais. Possui, também, vínculos fortes com serviços de saúde, como a Unidade de Pronto Atendimento (UPA), com o Ambulatório de Psiquiatria do Hospital e com a UAP, onde reinternou diversas vezes.

É maravilhoso o trabalho daqui, até minha irmã, que não vem aqui, sempre diz que o melhor lugar para o Alex estar é aqui, são todos muito atenciosos, tudo ótimo, tratam todos muito bem. (Ana) 
Família que convive com pessoa com transtorno mental: genograma e ecomapa| 10

Encaminhou-se Alex a um Centro de Atenção Psicossocial (CAPS), porém não houve adesão, sua permanência na maior parte do tempo é longe da família e do lar. Salienta-se que a família, bem como a equipe desta unidade identificou que há grande número de reinternações de Alex. Este alterna sua estadia entre a casa dos pais, onde permanece alguns dias, a UAP e instituições de longa permanência. Com efeito, muitas vezes, a institucionalização acontece devido à dificuldade que a família tem de cuidar da pessoa com transtorno mental, colocando ela e a si mesmo em risco.

Ele foi para casa, ficou uma semana e pouco, mas não dava mais, se soqueia, quebrou a térmica e se soqueava e soqueava as paredes e procurava faca para se esfaquear. (Ana)

Tinha que esconder tudo que era coisa de comer, de tudo, ele fazia que ia para lá para esperar, vinha correndo e me dava um empurrão, duas vezes ele me derrubou, mas ainda bem que eu caí sentada. (Ana)

Os pais relataram que Alex sofreu agressão física em uma das instituições e foi encontrado, por Abel, contido de maneira inadequada, com sua circulação prejudicada, estava desmaiado e com hematomas. Foi levado ao hospital, onde permaneceu alguns dias na Unidade de Terapia Intensiva (UTI), diagnosticado com pneumonia.

Ele estava contido com as tiras dessa finura assim, bem amarrado, as mãos estavam dessa grossura de inchada [...]. As mãos estavam roxas, os pés amarrados estavam roxos e ele, simplesmente, estava gelado e não [...]. Estava morrendo [...]. Quando eu terminei de desamarrar as mãos, não tinha desamarrado os pés, ele simplesmente apagou, não respirou mais, eu tive que massagear ele e ele não voltava, não voltava, até que uma hora deu um ronco e voltou. Não acharam oxigênio, disseram que não tinham, aí eu disse para chamar o SAMU [Serviço de Atendimento Móvel de Urgência], tem que socorrer ele! Desamarrei os pés dele e sentei ele para ele respirar melhor. (Abel)

A fala de Abel remete ao século passado, quando as pessoas com transtornos mentais ou consideradas "anormais" vivenciaram o modelo manicomial. Em relação à transformação desse modelo, vale ressaltar a dificuldade que os pais relataram ao sair com Alex na rua, pois desde adolescente ele sofre com o estigma e preconceito, como se observa na fala da mãe: 
Crises de fúria, de força, ficavam incomodando ele lá na faixa [rua], ficavam incomodando ele. (Ana)

No bairro onde a família reside há igreja, escola, Centro de Tradições Gaúchas (CTG) e Estratégia de Saúde da Família (ESF), pouco frequentada pela família. Há poucos locais para lazer e interação social.

\section{Discussão}

A construção compartilhada do genograma e ecomapa possibilitou que a família relatasse seu cotidiano e suas relações, tornando mais claros aspectos do seu contexto, o que pode ser relevante para o levantamento de dados e posterior intervenção. ${ }^{11}$ Faz-se indispensável a participação da família na construção dos diagramas, pois contribui para a criação de vínculo entre os participantes e o profissional de saúde, além de propiciar uma intervenção que contemple a integralidade da família. ${ }^{12}$

A família ser ausente ou vulnerável psicossocialmente pode ser um fator negativo no processo de saúde e doença, inclusive aumentando o tempo de internação. Ainda, a vulnerabilidade da família afeta a qualidade das relações, podendo colaborar ou não para o desgaste dos principais cuidadores e também dos profissionais envolvidos. ${ }^{13}$ Nota-se que, quando há pouca participação de alguns membros da família no cuidado, a sobrecarga de outros membros aumenta, gerando prejuízos relacionados a internação e relação entre os familiares.

Os familiares tornam-se os principais provedores de cuidados e apoio. Estes fatores também colaboram no aumento da sobrecarga, definida como sentimento de peso que a família carrega por executar o papel de cuidadora e das dificuldades encontradas ao desempenhar esse papel cotidianamente. A sobrecarga pode ser objetiva quando relacionada a tarefas cotidianas, perdas financeiras e mudança de rotina, ou subjetiva, quando envolve emoções e preocupações em relação à pessoa com transtorno mental. A sobrecarga familiar refere-se aos efeitos do transtorno psiquiátrico na família, e não à pessoa em si. $^{14}$ 
Família que convive com pessoa com transtorno mental: genograma e ecomapa| 12

As relações fortes, bem como o auxílio e apoio entre os familiares refletem no cuidado prestado, pois são fatores que propiciam mais segurança, conforto e tranquilidade para quem está cuidando. É uma forma de a família investir em maneiras de proporcionar bem-estar por meio de práticas que geram satisfação e ajuda mútua. ${ }^{15}$ Nota-se ainda que não há suporte de vizinhos, diferente do que outros estudos apontam. ${ }^{11,16}$

Em relação às práticas desenvolvidas na UAP, estas devem ser contempladas pela equipe multiprofissional, na busca de um cuidado humanizado. Além disso, cuidado integral, compreendido por uma relação estreita entre o profissional, o usuário e sua família. ${ }^{17}$ Apesar do vínculo da família com uma unidade de internação, é importante a vinculação com serviços substitutivos, pois isso faz parte do redirecionamento do modelo assistencial em saúde mental.

Ademais, faz-se necessária a rede de dispositivos que atendam as pessoas com transtornos mentais de forma aberta, comunitária e em seus territórios. Visto que os usuários e familiares sentem-se satisfeitos com estes serviços, isso pode estar atrelado ao cuidado integral, acolhimento, reinserção social, melhora na qualidade de vida e auxílio na relação com as pessoas com transtornos mentais. ${ }^{18}$

Nesse sentido, o CAPS configura-se como o espaço apropriado para realizar cuidado integral à pessoa com sofrimento psíquico intenso, buscar sua reinserção social, promover articulação com os demais serviços da rede, fortalecendo os vínculos entre a pessoa e sua família e evitando internações psiquiátricas. ${ }^{19}$ Para isso, evidencia-se a importância de investir na rede de saúde, no sentido de estimular solidariedade e identificar os potenciais recursos do território no processo de reabilitação psicossocial.

Entretanto, percebe-se que os serviços extra-hospitalares, ao invés de substituírem o modelo asilar, passam a compor a rede, coexistindo com serviços já existentes como os ambulatórios e os hospitais psiquiátricos. ${ }^{20}$ Salienta-se que a família não apontou justificativas 
para não adesão de Alex ao CAPS. Sabe-se que esses fatores podem estar relacionados a portagiratória, denominado pela literatura internacional de revolving-door. ${ }^{21}$

A porta-giratória pode ocorrer como uma consequência da desinstitucionalização quando essa é tratada como desospitalização. As políticas públicas preveem a redução de leitos psiquiátricos, sem viabilizar as condições necessárias para o atendimento extra-hospitalar, refletindo negativamente no cuidado ao usuário e família, acarretando nas reinternações. ${ }^{20}$ Dessa forma, o cuidado em saúde mental que deveria ser contínuo, acaba fragmentado, pois cada serviço realiza apenas o que considera ser de sua competência, sem que haja a comunicação necessária.

Nesse contexto, deve-se atentar para a questão da porta-giratória no processo da Reforma Psiquiátrica, como se evidenciou no presente estudo. Essa identificação é importante, pois estimula refletir a busca de estratégias para que esse fator seja minimizado, reforçando o processo de transformação do modelo de atenção à saúde mental.

Ademais, os Serviços Residenciais Terapêuticos (SRTs) podem ser um recurso, os quais são definidos como moradias destinadas às pessoas com transtornos mentais egressas de longas internações psiquiátricas, que não possuem suporte social ou laços familiares que viabilizem sua reinserção social. ${ }^{22}$ Entretanto, a cidade em que Alex reside não possui esse serviço, fazendo com que a opção de moradia seja a instituição de longa permanência para pessoas com baixo grau de autonomia e significantes problemas relativos ao comportamento social.

Referente ao modelo manicomial, evidenciado nos resultados, vale ressaltar que no período que antecede os movimentos da Reforma Psiquiátrica, as trocas sociais entre trabalhadores de saúde e as pessoas internadas eram extintas, como comunicação, afetividade e acolhimento. Não recebiam tratamento digno, muitas vezes sofriam violência e tinham suas potencialidades reduzidas até se tornarem incapazes de regressar ao convívio social. Ainda, realizava-se contenção mecânica com faixas inadequadas como forma de punição, ou seja, sem fins terapêuticos. ${ }^{23}$ 
Família que convive com pessoa com transtorno mental: genograma e ecomapa| 14

Atualmente utiliza-se a contenção mecânica, porém norteada pela Resolução 427/2012 do Conselho Federal de Enfermagem, que normatiza os procedimentos da enfermagem no emprego de contenção mecânica de pacientes. Deve-se realizar quando for o único meio possível para prevenir dano imediato ou iminente à pessoa ou aos demais, não podendo ser prolongada além do período estritamente necessário. Veda-se aos profissionais o emprego de contenção mecânica com propósito de disciplina, punição e coerção, ou por conveniência da instituição ou equipe de saúde. Ainda, deve-se monitorar a pessoa para prevenir a ocorrência de eventos adversos ou para identifica-los precocemente. ${ }^{24}$

Por fim, nota-se que há dificuldade em implementar a Reforma Psiquiátrica no que diz respeito à dimensão sociocultural, enfatizando o estigma, preconceito e exclusão. Nesse contexto, os profissionais de saúde têm papel importante como educador na sociedade, tendo em mente que trabalhar com a comunidade é um processo lento, pois envolve cultura e preconceitos arraigados.

\section{Conclusão}

A vulnerabilidade psicossocial da família que convive com pessoa com transtorno mental é um fator que repercute no processo de cuidado prestado a esta, considerando a importância e o papel que é atribuído aos familiares. Aliado a isso, os vínculos que a família possui entre si, bem como suas relações externas são fundamentais. Quando estas são frágeis ou inexistentes, a sobrecarga dos cuidadores aumenta e torna-se um obstáculo para o cuidado.

A escassez de serviços substitutivos que cumpram suas atribuições conforme prevê as políticas públicas, bem como a ausência de SRTs, contribuem para a porta-giratória, aumento de reinternações e institucionalização em instituições de longa permanência, dificultando o cuidado dispensado pelos familiares, no que diz respeito a pouca oferta de espaços de reabilitação, acolhimento e relações interpessoais. Isso aponta a necessidade de investimento e qualificação de serviços de saúde ou especializados para atenderem a demanda em saúde 
mental. Além do mais, a importância de propiciar espaços para convivência e lazer para pessoas com transtornos mentais e sua família.

Os profissionais que assistem a família podem buscar instrumentos, como o genograma e o ecomapa, para auxiliar no seu trabalho com intuito de melhor compreender o contexto em que a família está inserida, suas potencialidades, suas fragilidades, sua estrutura, seus vínculos e sua rede de apoio, que poderão auxiliar na elaboração de estratégias de intervenção que auxiliem na promoção e recuperação da saúde.

Este estudo contribui com o ensino e a prática de enfermagem ao discutir estratégias de avaliação e intervenção para as famílias, na medida em que possibilita maior compreensão acerca da corresponsabilização no cuidado e recursos disponíveis. Além disso, pode contribuir na reflexão de ações de apoio voltadas às famílias.

Considerando que o estudo foi realizado sem a presença da pessoa índice e em contexto hospitalar, cabe expandir as investigações com vistas a abranger tais aspectos. Entrevistas realizadas no lar, fora das dependências de um hospital e/ou com pessoas que não estejam internadas podem fomentar discussões sob outra perspectiva.

Sugere-se a implementação do genograma e ecomapa na assistência a pessoas com transtornos mentais, pois são ferramentas que fornecem informações importantes para o planejamento do cuidado e intervenções no contexto familiar. Pode ser utilizada por enfermeiros e/ou outros membros da equipe multiprofissional, com vistas a fortalecer o cuidado integral.

\section{Referências}

1. Brasil, Ministério da Saúde (BR). Cadernos de atenção básica: Saúde mental. Brasília (DF): Ministério da Saúde; 2013.

2. Kebbe LM, Rôse LBR, Fiorati RC, Carretta RYD. Cuidando do familiar com transtorno mental: desafios percebidos pelos cuidadores sobre as tarefas de cuidar. Saúde Debate [Internet]. 2014 [acesso em 2017 nov

14];38(102):494-505.

Disponível em: 
Família que convive com pessoa com transtorno mental: genograma e ecomapa| 16

http://www.scielo.br/scielo.php?script=sci_arttext\&pid=S0103-11042014000300494\&lng=en

doi: http://dx.doi.org/10.5935/0103-1104.20140046

3. Souza Filho MD, Sousa AO, Parente ACBV, Carvalho MCC, Martins MCC. Avaliação da sobrecarga em familiares cuidadores de pacientes esquizofrênicos adultos. Psicol Estud [Internet]. 2010 [acesso em 2017 nov 14];15(3):639-47. Disponível em: http://www.scielo.br/pdf/pe/v15n3/v15n3a22.pdf

4. Santin G, Klafke TE. A família e o cuidado em saúde mental. Barbarói [Internet]. 2011 [acesso em 2017 dez 12];34. Disponível em: https://online.unisc.br/seer/index.php/barbaroi/article/view/1643/1567

5. Soares CB, Munari DB. Considerações acerca da sobrecarga em familiares de pessoas com transtornos mentais. Ciênc Cuid Saúde [Internet]. 2007 [acesso em 2017 set 05];6(3):357-62. Disponível em: http://periodicos.uem.br/ojs/index.php/CiencCuidSaude/article/view/4024/2717

6. Musquim CA, Araújo LFS, Bellato R, Dolina JV. Genograma e ecomapa: desenhando itinerários terapêuticos de família em condição crônica. Rev Eletrônica Enferm [Internet]. 2013 [acesso em 2018 jan 11];15(3):656-66. Disponível em: https://www.fen.ufg.br/revista/v15/n3/pdf/v15n3a07.pdf

7. Dezoti AP, Alexandre AMC, Freire MHS, Mercês NNA, Mazza VA. Apoio social a famílias de crianças com paralisia cerebral. Acta Paul Enferm [Internet]. 2015 [acesso em 2018 out 15];28(2):172-6. Disponível em: http://www.scielo.br/scielo.php?script=sci_arttext\&pid=S0103-21002015000200172\&lng=pt

8. Vicente JB, Higarashi IH, Furtado MCC. Transtorno mental na infância: configurações familiares e suas relações sociais. Esc Anna Nery Rev Enferm [Internet]. 2015 [acesso em 2018 jan 25];19(1):107-14. Disponível em: http://www.scielo.br/scielo.php?script=sci_arttext\&pid=S1414-81452015000100107\&lng=pt

9. Wright LM, Leahey M. Enfermeiras e famílias: um guia para avaliação e intervenção na família. 5ª ed. São Paulo (SP): Roca; 2011.

10. Brasil. Ministério da Saúde. Conselho Nacional de Saúde. Resolução no 466, de 12 de dezembro de 2012 [Internet]. 2012 [acesso em 2017 dez 05]. Disponível em: http://bvsms.saude.gov.br/bvs/saudelegis/cns/2013/res0466_12_12_2012.html

11. Garcia RP, Budó MLD, Viegas AC, Cardoso DH, Schwartz E, Muniz RM. Estrutura e vínculos de uma família após infarto agudo do miocárdio. Rev Cuid (Bucaramanga 2010) [Internet]. 2015 [acesso em 2017 nov 26];6(1):991-8. Disponível em: http://www.scielo.org.co/scielo.php?script=sci_arttext\&pid=S221609732015000100016\&lng=en\&nrm=iso\&tlng=pt

12. Borges CD, Costa MM, Faria JG. Genograma e atenção básica à saúde: em busca da integralidade. Revista Psicol Saúde [Internet]. 2015 [acesso em 2017 dez 11];7(2):133-41. Disponível em: http://pepsic.bvsalud.org/pdf/rpsaude/v7n2/v7n2a07.pdf

13. Pereira Neto EF, Ramos MZ, Silveira EMC. Configurações familiares e implicações para o trabalho em saúde da criança em nível hospitalar. Physis (Rio J) [Internet]. 2016 [acesso em 2018 fev 01];26(3):961- 
79. Disponível em: http://www.scielo.br/scielo.php?script=sci_arttext\&pid=S010373312016000300961\&lng=en http://dx.doi.org/10.1590/s0103-73312016000300013 doi: http://dx.doi.org/10.1590/S0103-73312016000300013

14. Nolasco M, Bandeira M, Oliveira MS, Vidal CEL. Sobrecarga de familiares cuidadores em relação ao diagnóstico de pacientes psiquiátricos. J Bras Psiquiatr [Internet]. 2014 [acesso em 2017 nov 01];63(2):8997. Disponível em: http:/www.scielo.br/scielo.php?script=sci_arttext\&pid=S004720852014000200089\&lng=en doi: http://dx.doi.org/10.1590/0047-2085000000011

15. Oliveira APP, Caldana RHL. As repercussões do cuidado na vida do cuidador familiar do idoso com Demência de Alzheimer. Saúde Soc [Internet]. 2012 [acesso em 2018 jan 15];21(3):675-85. Disponível em: http://www.revistas.usp.br/sausoc/article/viewFile/48754/52828

16. Souza IP, Bellato R, Araújo LFS, Almeida KBB. Genogram and ecomap as tools for understanding family care in chronic illness of the young. Texto \& Context Enferm [Internet]. 2016 [acesso em 2017 out 22];25(4):e1530015. Disponível em: http://www.scielo.br/scielo.php?script=sci_arttext\&pid=S010407072016000400301\&lng=en

17. Campos Junior A, Amarante PDC. Estudo sobre práticas de cuidado em saúde mental na Atenção Primária: o caso de um município do interior do estado do Rio de Janeiro. Cad Saúde Coletiva [Internet]. 2015 [acesso em 2017 dez 01];23(4):425-35. Disponível em: http://www.scielo.br/scielo.php?script=sci_arttext\&pid=S1414-462X2015000400425\&lng=en

18. Costa PHA, Colugnati FAB, Ronzani TM. Avaliação de serviços em saúde mental no Brasil: revisão sistemática da literatura. Ciênc Saúde Colet [Internet]. 2015 [acesso em 2017 nov 01];20(10):3243-53. Disponível em: http:/www.scielo.br/scielo.php?script=sci_arttext\&pid=S141381232015001003243\&lng=en

19. Oliveira EC, Medeiros AT, Trajano FMP, Chaves Neto G, Almeida SA, Almeida LR. Mental health care in the territory: conceptions of primary health care professionals. Esc Anna Nery Rev Enferm [Internet]. 2017 [acesso em 2017 out 15];21(3):e20160040. Disponível em: http://www.scielo.br/scielo.php?script=sci_arttext\&pid=S1414-81452017000300210

20. Pande MNR, Amarante PDC. Desafios para os Centros de Atenção Psicossocial como serviços substitutivos: a nova cronicidade em questão. Ciênc Saúde Colet [Internet]. 2011 [acesso em $2017 \mathrm{dez}$ 13];16(4):2067-76. Disponível em: http://www.scielo.br/scielo.php?script=sci_arttext\&pid=S1413$81232011000400006 \& \operatorname{lng}=\mathrm{pt}$

21. Barron GR. The Alberta Mental Health Act 2010 and revolving door syndrome: control, care, and identity in making up people. Can Rev Sociol [Internet]. 2016 [acesso em 2019 jan 29];53(3):290-315. Disponível em: https://www.ncbi.nlm.nih.gov/pubmed/27527994 
Família que convive com pessoa com transtorno mental: genograma e ecomapa| 18

22. Silva PRF, Carvalho MCA, Cavalcanti MT, Echebarrena RC, Mello AS, Dahl CM, et al. Deinstitutionalization of long stay patients in a psychiatric hospital in Rio de Janeiro. Ciênc Saúde Colet [Internet]. 2017 [acesso em 2017 dez 20];22(7):2341-52. Disponível em: http://www.scielo.br/scielo.php?script=sci_arttext\&pid=S1413-81232017002702341\&lng=en

23. Guimarães AN, Borba LO, Larocca LM, Maftum MA. Mental health treatment according to the asylum model (1960 to 2000): nursing professionals' statements. Texto \& Context Enferm [Internet]. 2013 [acesso em 2017 jan 16];22(2):361-9. Disponível em: http://www.scielo.br/scielo.php?script=sci_arttext\&pid=S0104-07072013000200012\&lng=en

24. Brasil. Conselho Federal de Enfermagem. Resolução COFEN no 427 de 7 de maio de 2012. Normatiza os procedimentos da enfermagem no emprego de contenção mecânica de pacientes [Internet]. 2012 [acesso em 2017 set 22]. Disponível em: http://www.cofen.gov.br/resoluo-cofen-n-4272012_9146.html

\section{Autor correspondente}

Ariane Naidon Cattani

E-mail: arianecattani@yahoo.com.br

Endereço: Av. Roraima n 1000 - Cidade Universitária

Centro de Ciências da Saúde/PPGENF - Prédio 26

Bairro Camobi - Santa Maria, RS, Brasil

CEP: $97105-900$

\section{Contribuições de Autoria}

\section{1 - Ariane Naidon Cattani}

Concepção e projeto, análise e interpretação dos dados, redação do artigo, revisão crítica relevante do conteúdo intelectual, aprovação final da versão a ser publicada.

\section{2 - Ana Paula Vargas Ronsani}

Concepção e projeto, análise e interpretação dos dados, revisão crítica relevante do conteúdo intelectual, aprovação final da versão a ser publicada.

\section{3 - Lisiane dos Santos Welter}

Concepção e projeto, análise e interpretação dos dados, revisão crítica relevante do conteúdo intelectual, aprovação final da versão a ser publicada.

\section{4 - Amanda de Lemos Mello}

Concepção e projeto, análise e interpretação dos dados, redação do artigo, revisão crítica relevante do conteúdo intelectual, aprovação final da versão a ser publicada. 
19 | Cattani AN, Ronsani APV, Welter LS, Mello AL, Siqueira DF, Terra MG

\section{5 - Daiana Foggiato de Siqueira}

Concepção e projeto, análise e interpretação dos dados, redação do artigo, revisão crítica relevante do conteúdo intelectual, aprovação final da versão a ser publicada.

\section{6 - Marlene Gomes Terra}

Concepção e projeto, análise e interpretação dos dados, revisão crítica relevante do conteúdo intelectual, aprovação final da versão a ser publicada.

\section{Como citar este artigo}

Cattani AN, Ronsani APV, Welter LS, Mello AL, Siqueira DF, Terra MG. Família que convive com pessoa com transtorno mental: genograma e ecomapa. Rev. Enferm. UFSM. 2020 [Acesso em: Ano Mês Dia]; vol.10 e:1-19. DOI:https://doi.org/10.5902/2179769236517 